ARTIGOS

\section{PRODUÇÃO INTERNACIONAL SOBRE ENGAJAMENTO NO TRABALHO NO PERÍODO DE 2011 A 2020: UM ESTUDO BIBLIOMÉTRICO}

INTERNATIONAL PRODUCTION ON WORK

ENGAGEMENT IN THE PERIOD 2011 TO 2020: A BIBLIOMETRIC STUDY

\section{RESUMO}

O objetivo deste artigo foi apresentar a produção científica acerca do tema engajamento no trabalho (EGT) com vistas a identificar lacunas da produção científica e destacando sua importância no campo do bem-estar no trabalho. Trata-se de uma pesquisa descritiva, com abordagem quantitativa dos dados coletados por meio da bibliometria, técnica de medição da produção e disseminação do conhecimento científico. Para tanto, realizaram-se buscas na Web of Science (WOS), no período de 2011 a 2020. Os resultados demonstram a existência de 2.797 artigos publicados, com distribuição temporal indicando tendência de crescimento linear, sendo o artigo escrito por Christian, Garza e Slaughter (2011) o mais influente da década, e Arnold B. Bakker, o autor mais citado. Esta pesquisa contribui para o sentido de apresentar que, apesar dos avanços epistemológicos e metodológicos significativos no campo, a supremacia de Bakker e de sua equipe sugere linearidade com apenas uma corrente teórica.

Palavras-chave: Engajamento no Trabalho. Psicologia Positiva. Revisão Bibliométrica. Comportamento Organizacional. Gestão de Pessoas.

Dian Carla Dias Isidorio

Bombazaro

dian.carla@sc.senac.br Mestranda em Administração pela Universidade de Passo

Fundo. Coordenadora

Educacional do Núcleo Superior da Faculdade Senac Concórdia. Concórdia, SC, BR.

Denize Grzybovski gdenize@upf.br Doutora em Administração. Docente da Universidade de Passo Fundo. Passo Fundo, RS, BR.

\section{ABSTRACT}

The purpose of this article was to present scientific production on the topic engagement at work (EGT) with a view to identifying gaps in scientific production and highlighting its importance in the field of well-being at work. This is a descriptive study, with a quantitative approach to the data collected through bibliometrics, a technique for measuring the production and disseminating of scientific knowledge. To 
this end, searches were carried out on the Web of Science (WOS) from 2011 to 2020. The results demonstrate the existence of 2,797 published articles, with temporal distribution indicating a linear growth trend, with the article written by Christian, Garza and Slaughter (2011) being the most influential of the decade, and Arnold B. Bakker the most cited author. This research contributes towards presenting that despite the significant epistemological and methodological advances in the field, the supremacy of Bakker and his team suggests linearity with only one theoretical current.

Keywords: Work engagement. Positive Psychology. Bibliometric Review. Organizational Behavior. Human Resource Management.

\section{INTRODUÇÃO}

As primeiras pesquisas sobre engajamento no trabalho (EGT) foram desenvolvidas por Kahn (1990), o qual conceituou o engajamento psicológico na área da Psicologia do Trabalho, e decorrem da corrente do humanismo que emergiu na década de 1950 (ANGST; BENEVIDES-PEREIRA; PORTO-MARTINS, 2009). No entanto, foi somente na década de 1990 que a psicologia positiva retoma a visão positiva do ser humano (ANGST; BENEVIDES-PEREIRA; PORTO-MARTINS, 2009) e resgata um olhar sobre os aspectos salutogênicos com a pretensão de superar o redutivismo dominante. A psicologia positiva proporcionou mudanças na forma de estudar atitudes e experiências dos trabalhadores no ambiente organizacional, por meio das dimensões do engajamento no trabalho (RODRÍGUEZ-MONTALBÁN; MARTÍNEZ-LUGO; SÁNCHEZ-CARDONA, 2014). Devido à relevância desse construto para as organizações compreenderem fatores psicossociais dos seus trabalhadores, o engajamento é conceituado como um estado motivacional positivo e de bem-estar das pessoas no ambiente de trabalho (RODRÍGUEZ-MONTALBÁN; MARTÍNEZ-LUGO; SÁNCHEZ-CARDONA, 2014), ou seja, um estado positivo da mente, realizador e relacionado ao trabalho caracterizado pelo vigor, dedicação e absorção (SCHAUFELI; BAKKER, 2010). ${ }^{1}$ Esse mesmo entendimento é seguido por González-Roma et al. (2006), Bakker (2011) e Bakker, Albrecht e Leiter (2011).

Por meio do engajamento, os indivíduos apresentam emoções positivas, como felicidade, alegria, otimismo, autoconfiança, esperança, mentalidade futura, coragem, espiritualidade, perseverança (SELIGMAN; CSIKSZENTMIHALYI, 2001; BAKKER, 2011; OLIVEIRA; ROCHA, 2017). Por conseguinte, apresentam menos doenças psicossomáticas, como dores de cabeça e tensão muscular (SCHAUFELI; DIJKSTRA; VASQUEZ, 2013; HANSEN et al., 2018), aumentando sua capacidade de resiliência e de comprometimento com o trabalho (CHÉR, 2016; MOURA; CHARÃO-BRITO; LOPES, 2017). Dessa forma, engajamento no trabalho é visto como o oposto do Burnout (SCHAUFELI; BAKKER, 2003).

No entanto, a comunidade epistêmica pode estar dispersa ou centrada em apenas uma corrente teórica. Essa problemática é levantada a partir do momento que se tenta construir uma agenda de pesquisa. Obregon et al. (2016) constataram que, mesmo existindo uma quantidade substancial de publicações sobre o tema, há um campo vasto a ser explorado. Fiorentin, Stefano e Santos (2020) constataram que a predominância é de estudos conduzidos por auto-

1 Tradução realizada pelos membros do Grupo de Estudos e Pesquisas Sobre Estresse e Burnot (Rosana Angst, Ana Maria T. Benevides-Pereira e Paulo C. Porto-Martins), em abril de 2009, do original UWES Utrecht Work Engagement Scale: preliminary manual [versão 1, novembro 2003), escrito por Wilmar Schaufeli e Arnold Bakker. Disponível na versão em português brasileiro, no link: https://www.wilmarschaufeli. nl/publications/Schaufeli/Test\%20Manuals/Test_manual_UWES_Brazil.pdf. 
res holandeses, publicados em periódicos das áreas de gestão e de psicologia e cujo objetivo central é correlacionar engajamento com outros constructos na área de gestão de pessoas. Moraes e Teixeira (2020) indicam outras possibilidades de estudo do engajamento no trabalho ao associá-lo ao constructo percepção política na organização (PPO), sugerindo que as dimensões do engajamento no trabalho podem ser mais efetivas do que as tentativas de coibir comportamentos políticos.

O objetivo deste artigo foi apresentar a produção científica sobre o tema engajamento no trabalho (EGT), por meio das publicações depositadas na base de dados Web of Science (WOS) do Institute for Scientifuc Information (ISI), no período de 2011 a 2020, com vistas a identificar lacunas da produção científica e destacando sua importância no campo do bem-estar no trabalho a fim de responder às seguintes questões de pesquisa: como ocorreu a evolução da produção científica internacional sobre EGT na última década? A referida produção está indicando perspectivas teóricas alternativas ou segue seu curso em uma linearidade, tanto de temas, quanto de autores, como apontaram Fiorentin, Stefano e Santos (2020)?

Toma-se a WOS como base de dados, porque possibilita a identificação de artigos em periódicos em diferentes áreas de conhecimento, sendo possível identificar os autores mais relevantes que publicam em determinada temática, bem como por referência citada. Outro fator relevante é a possibilidade de pesquisa ampliada, sendo possível refinar a pesquisa por assunto, tipo de documento, título da fonte, autores, ano de publicação, país de filiação dos autores e instituições que representam centros de referência de estudos sobre o tema.

Este artigo compõe-se de cinco partes: a primeira refere-se à introdução; a segunda apresenta fundamentação teórica; a terceira aborda a metodologia utilizada na pesquisa; na quarta parte, são apresentados os resultados e as discussões e, por último, a quinta parte contém as considerações finais.

\section{ENGAJAMENTO NO TRABALHO}

As pesquisas sobre a psicologia positiva nas organizações deram origem aos estudos sobre engajamento no trabalho. No contexto internacional, Vazquez e Hutz (2018, p. 24) ressalta o "vínculo de prazer da pessoa com o trabalho", o qual gera aumento dos recursos pessoais e físicos, eleva o grau de engajamento com efeitos positivos no desempenho individual e na redução dos índices de absenteísmo. Em contraste, o baixo nível de engajamento no trabalho diminui o bem-estar e o desempenho no trabalho, afirmam Knight, Patterson e Dawson (2017), mas eles apontam escassez nos estudos sobre evidências de intervenções.

Kahn (1990), pioneiro nos estudos sobre engajamento no trabalho, explica que pessoas engajadas envolvem-se com tarefas cognitivas e emocionalmente, tendo em vista que os fatores individuais e organizacionais influenciam a experiência psicológica de trabalho e que esta experiência influencia no comportamento. Nesse sentido, Mäkikangas (2018) constatou, ainda, que o engajamento no trabalho está associado com o perfil ativo do trabalhador, de forma que as estratégias desafiadoras por eles adotadas nas demandas de trabalho aumentam o nível de engajamento.

Maslach, Schaufeli e Leiter (2001) contribuem com o debate teórico sobre engajamento no trabalho ao afirmar que a conexão psicológica com a execução das atividades no ambiente de trabalho não se limita a uma atitude em relação aos recursos da organização no trabalho, mas diz respeito ao autoinvestimento de recursos pessoais no trabalho (CHRISTIAN; GARZA; SLAUGHTER, 2011), estabelecendo uma correlação com o estado positivo da pessoa.

$\mathrm{O}$ engajamento no trabalho é mais, frequentemente, definido como um estado positivo relacionado ao trabalho mental que se caracteriza pelo vigor, dedicação e absorção (SCHAUFELI et al., 2002; SCHAUFELI; BAKKER, 2010; BAKKER, 2011). Os funcionários que estão envolvidos em seu trabalho são totalmente conectados com seus papéis de 
trabalho, apresentam mais energia e dedicação na realização das atividades (KNIGHT; PATTERSON; DAWSON, 2017; MÄKIKANGAS, 2018). Por essa razão, retoma-se a afirmação de Bakker (2011) a respeito da diferença entre engajamento no trabalho e satisfação no trabalho por engajamento combinar trabalho e prazer (dedicação) com alta ativação (vigor, absorção), enquanto satisfação no trabalho é, tipicamente, uma forma mais passiva do empregado.

Ainda relacionado com o estado positivo da pessoa no trabalho, engajamento se caracteriza pelo vigor, dedicação e absorção. Vigor é caracterizado por altos níveis de energia para investir esforço em seu trabalho e persistência, mesmo perante as dificuldades. Dedicação é caracterizada por uma sensação de entusiasmo, inspiração, orgulho e desafio. Absorção é caracterizada por ser totalmente concentrada e profundamente envolvida com o trabalho, pelo que o tempo passa rapidamente, sendo totalmente absorvido em seu trabalho (SCHAUFELI et al., 2002; BAKKER, 2011).

Existem, no mínimo, quatro razões pelas quais os trabalhadores engajados têm melhor desempenho do que os trabalhadores desengajados. Em primeiro lugar, os funcionários envolvidos, muitas vezes, experimentam emoções positivas, incluindo gratidão, alegria e entusiasmo. Em segundo lugar, os trabalhadores envolvidos podem-se concentrar e dedicar todas as suas habilidades e recursos energéticos para o seu trabalho. Em terceiro lugar, os funcionários envolvidos podem criar seus próprios recursos de trabalho e pessoais. Finalmente, os trabalhadores envolvidos transformam seu envolvimento com os outros em seu ambiente de trabalho (BAKKER; XANTHOPOULOU, 2009), uma vez que, na maioria das organizações, desempenho é o resultado do esforço de colaboração (BAKKER, 2011).

Mas, quando o funcionário está desequilibrado, não está de acordo com suas escolhas de vida e carreira e não se sente inserido na organização, com isso, dificilmente produzirá um resultado diferente do comportamento não engajado (CHÉR, 2016). Estudos têm demons- trado que o engajamento no trabalho está relacionado, positivamente, com o desempenho do trabalho, com os desafios do cargo (KNIGHT; PATTERSON; DAWSON, 2017; MÄKIKANGAS, 2018), mas também com os mecanismos de compensações, como descrevem Venz, Pundt e Sonnentag (2017).

De acordo com Schaufeli, Dijkstra e Vazquez (2013, p. 16), os benefícios do engajamento no trabalho são descritos por indicadores objetivos, como desempenho superior dos setores em que atuam pessoas engajadas, pelas maiores notas verificadas em estudantes engajados e pelo menor índice de turnover nas empresas que possuem funcionários engajados. Mas também são observados comportamentos positivos, como a predisposição de pessoas engajadas aceitarem realizar tarefas desafiadoras (MÄKIKANGAS, 2018), gestores engajados serem percebidos como líderes por sua equipe de trabalho e atuarem na perspectiva da liderança transformacional (WANG; LI; LI, 2017) e a menor incidência de erros e acidentes no seu ambiente de trabalho. Depreende-se, portanto, que pessoas engajadas se divertem no ambiente do trabalho, seu desempenho é positivo em relação àquilo que a empresa espera deles e são pessoas que se sentem confortáveis consigo mesmo. Complementarmente, como constataram Wang, Li e Li (2017), afirmamos que o engajamento no trabalho está associado, positivamente, com resilência e liderança transformacional.

Em síntese, adotar práticas que produzem engajamento não só contribui para maior desempenho no trabalho, mas também é um importante indicador gerencial do bem-estar das pessoas no trabalho (CHÉR, 2016), superando a validade dos tradicionais indicadores de satisfação e motivação até então utilizados na área de gestão de pessoas, por apresentarem relação direta no desempenho organizacional, como afirmam Constâncio e Souza Neto (2016).

De acordo com os fundamentos da Psicologia Organizacional, engajamento no trabalho e psicologia positiva estão relacionados e são opostos à síndrome de Burnout (SCHAUFELI; BAKKER, 2010). Enquanto os primeiros têm 
potencial contributivo para melhoria da qualidade de vida dos trabalhadores (SELIGMAN; CSIKSZENTMIHALYI, 2001), o segundo representa sintomas de adoecimento no trabalho, como esgotamento associado a um estado de estresse crônico (SCHAUFELI; BAKKER, 2010). Trabalhadores mais felizes e otimistas se destacam entre os membros do grupo de trabalho, por serem mais criativos, inovadores e empreendedores e por manterem relacionamentos saudáveis. Portanto, é possível que, quando pessoas engajadas atuam em nível gerencial, podem melhorar o desempenho organizacional e diferenciar uma organização de outra, bem como uma unidade operacional de outra na mesma organização. Contudo, é possível que o tema não está sendo desenvolvido nessa abordagem teórica, razão pela qual se propõe a realização de uma pesquisa bibliométrica.

\section{METODOLOGIA}

$\mathrm{O}$ estudo configura-se como uma pesquisa bibliométrica (CHUEKE; AMATUCCI, 2015; QUEVEDO-SILVA et al. 2016; GUERRAZZI et al., 2017), que visa mapear a produção científica sobre o engajamento no trabalho no período 2010 a 2020. A bibliometria, uma técnica quantitativa de medição de produção e difusão do conhecimento científico (ARAÚJO, 2006), pode ser desenvolvida como um estudo descritivo (produtividade obtida pela contagem das publicações) e avaliativo (uso a literatura para realizar a contagem de referências e citações. Conforme relatam Silva, Hayashi e Hayashi (2011), a contagem de citações é especialmente útil, pois se configura como um indicador de valor científico da pesquisa que pode auxiliar na identificação de tendências, dispersão/concentração de campos científicos, autores, instituições e periódicos. Por essa razão, este estudo descreveu a quantidade de artigos publicados em periódicos internacionais e avaliou as citações dos artigos publicados com vistas a identificar correntes teóricas e autores de referência no debate.

Para tanto, seguiram-se os passos da bibliometria descritos por Vasconcelos (2014), os quais são (i) definição da questão de pesquisa, seus objetivos e métodos; (ii) escolha da base de dados para coletar os dados; (iii) definição do software que será utilizado para a coleta de dados e as técnicas estatísticas para tratar os dos dados coletados; (iv) coleta dos dados; (v) tratamento dos dados.

Desse modo, essa bibliometria seguiu as cinco etapas descritas por Vasconcelos (2014), como é apresentado no quadro 1.

Quadro 1 - Etapas da revisão bibliométrica realizada

\begin{tabular}{|l|l|}
\hline \multicolumn{1}{|c|}{ ETAPAS } & \multicolumn{1}{c|}{ DESCRIÇÃO } \\
\hline Questões de pesquisa & $\begin{array}{l}\text { Como ocorreu a evolução da produção científica internacional sobre EGT na } \\
\text { última década? }\end{array}$ \\
& $\begin{array}{l}\text { A referida produção está indicando perspectivas teóricas alternativas ou segue } \\
\text { seu curso em uma linearidade, tanto de temas, quando de autores, como apon- } \\
\text { taram Fiorentin, Stefano e Santos (2020)? }\end{array}$ \\
\hline $\begin{array}{l}\text { Objetivo geral e objeti- } \\
\text { vos específicos }\end{array}$ & $\begin{array}{l}\text { Fazer o levantamento da produção científica sobre o tema engajamento no } \\
\text { trabalho (EGT) no período de 2011 a 2020. } \\
\text { Descrever a evolução dos estudos sobre engajamento no trabalho em termos } \\
\text { de temas e autores. } \\
\text { Identificar a(s) corrente(s) teórica(s) e autores de referência, as lacunas na } \\
\text { produção científica e destacar a importância do tema no campo de estudos do } \\
\text { bem-estar no trabalho. }\end{array}$ \\
\hline
\end{tabular}




\begin{tabular}{|c|c|}
\hline Método & $\begin{array}{l}\text { Técnicas bibliométricas descritiva e avaliativa, que consistem na apresentação } \\
\text { da produtividade internacional sobre o tema engajamento no trabalho obtida, } \\
\text { pela contagem das publicações, das referências e citações, seguindo os proce- } \\
\text { dimentos descritos por Araújo (2006) e Silva, Hayashi e Hayashi (2011). }\end{array}$ \\
\hline Base de dados & $\begin{array}{l}\text { Trabalhos científicos publicados nos periódicos disponíveis na base de dados } \\
\text { internacional Web of Science (WOS), Coleção Principal (Science \& Social } \\
\text { Science), por conter todos os periódicos que estão no JCR. }\end{array}$ \\
\hline $\begin{array}{l}\text { Softwares e ferramenta } \\
\text { estatística }\end{array}$ & $\begin{array}{l}\text { Os dados coletados foram organizados em planilhas eletrônicas no formato } \\
\text { "linha/coluna" usando o software Microsoft巴 Excel® para Microsoft } 365 \\
\text { MSO, versão } 2104 \text {. } \\
\text { A ferramenta estatística utilizada foi a Estatística Descritiva simples, aplicada } \\
\text { aos dados dispostos em tabelas, quadro e gráficos construídos na planilha ele- } \\
\text { trônica usando o próprio Microsoft Excel®. }\end{array}$ \\
\hline Coleta de dados & $\begin{array}{l}\text { A busca dos dados se deu em etapas, realizadas entre os meses de janeiro a } \\
\text { junho de } 2020 \text {, iniciando-se pela identificação da produção científica sobre o } \\
\text { tema central usando a expressão "work engagement" (engajamento no traba- } \\
\text { lho) como campo de busca (topic) da WOS. } \\
\text { O recorte temporal foi definido como sendo o período de 2011-2020, tendo em } \\
\text { vista que Fiorentin, Stefano e Santos (2020) já haviam investigado a produção } \\
\text { de artigos internacionais sobre o tema no período de 2008-2018 e constatado } \\
\text { que havia predominância de estudos de autores holandeses, com abordagem } \\
\text { quantitativa em revistas da área de gestão e psicologia. } \\
\text { Na sequência, iniciou-se a segunda etapa da pesquisa, na qual foi mantido o } \\
\text { recorte temporal pelos anos } 2011 \text { a } 2020 \text { (última década) e incluso os seguin- } \\
\text { tes parâmetros de busca: área de gestão (categorias management e business do } \\
\text { WOSß) e tipo de documento (artigos). } \\
\text { Critérios de inclusão: todas as publicações sobre a temática no período de } \\
2011 \text { a } 2020 \text {, exclusivamente do tipo de publicação "artigo" e na área de ges- } \\
\text { tão, categorias "management" e "business" do WOS. }\end{array}$ \\
\hline Tratamento dos dados & $\begin{array}{l}\text { Usando a técnica de análise de dados estatística descritiva simples, os dados } \\
\text { foram expostos em gráficos, tabelas e quadros de forma que fossem extraídas } \\
\text { informações sobre o nome dos autores dos artigos mais citados, número de } \\
\text { citações de cada artigo, relevância de periódicos. } \\
\text { À luz da literatura no campo do bem-estar no trabalho, os dados foram } \\
\text { submetidos à análise das possíveis lacunas na produção científica internacional, } \\
\text { corrente teórica e autores predominantes. }\end{array}$ \\
\hline
\end{tabular}

Fonte: elaborado pelas autoras (2020).

Com base nas etapas apresentadas, procedeu-se à avaliação da produção científica, ao mapeamento e à medição da produção e da produtividade científica, à descrição de aspectos importantes referentes ao tema engajamento no trabalho de forma a complementar e atualizar o estudo anterior realizado por Fiorentin, Stefano e Santos (2020). Os resultados são apresentados e discutidos na seção "apresentação e discussões", conforme recomendam Araújo (2006), Silva, Hayashi e Hayashi (2011) e Vasconcelos (2014). 


\section{RESULTADOS E DISCUSSÕES}

Para as buscas na base de dados da WOS, utilizou-se o descritor "work engajament" (engajamento no trabalho) como campo de busca (topic). Desse modo, a busca preliminar retornou com 9.949 publicações realizadas em diferentes áreas do conhecimento, com destaque para a Grande Área de Humanas (Educação, 19,19\%; Psicologia, 15,04\%) e das Ciências Sociais Aplicadas, com Administração sendo a disciplina com maior representatividade $(11,85 \%)$.

Na segunda fase da pesquisa, foram aplicados filtros com os seguintes parâmetros de busca: área de gestão (categorias management e business do WOS®) e tipo de documento (artigos). No período de dez anos, foram localizados 2.797 artigos, visto que a predominância dos registros se encontrava na categoria management $(82,94 \%)$. Sem exclusão dos registros repetidos, foi verificado que o debate sobre o tema está na categoria business $(30,85 \%)$ e em categorias correlatas à gestão, com destaque para psicologia aplicada $(24,02 \%)$, relações de trabalho $(7,68 \%)$, hospitalidade, turismo e lazer $(3,61 \%)$.

A distribuição temporal dos referidos artigos é apresentada no gráfico 1, indicando tendência de crescimento nas publicações internacionais sobre o tema. No período de 2011 a 2020, verifica-se um crescimento linear de 96 registros em 2011 para 598 registros em 2019. E, nos primeiros 6 meses do ano 2020, já havia 286 registros, indicando a mesma tendência de crescimento linear.

Gráfico 1 - Registros anuais da produção científica internacional sobre engajamento no trabalho

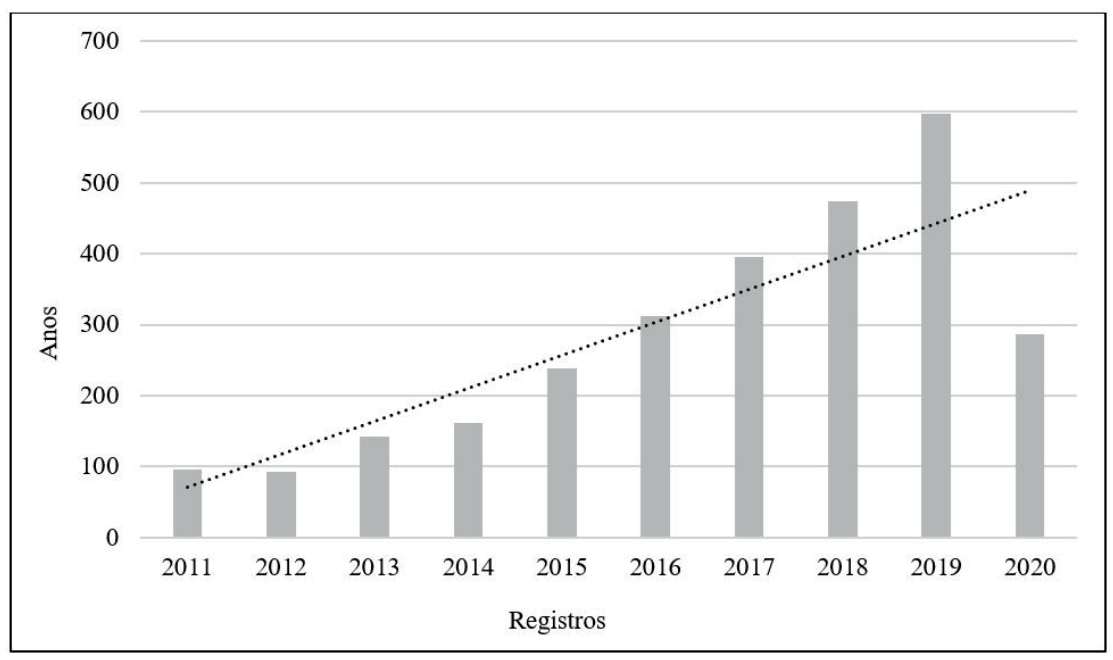

Fonte: dados da pesquisa (2020).

Nesse período analisado, o artigo escrito por Christian, Garza e Slaughter (2011) foi o mais citado (779 citações), seguido por Stilgoe, Owen e Macnaghten (2013), com 582 citações, Nahrgang, Morgeson e Hofmann (2011), com 530 citações, Bakker, Albrecht e Leiter (2011), com 416 citações e Bakker, Demerouti e Sanz-Vergel (2014), com 411 citações. No conjunto, os cinco artigos receberam 2.718 citações em uma década, como mostra a tabela 1, sendo Arnold B. Bakker coautor em nove dos 50 artigos mais citados na década 2010. 
Tabela 1 - Artigos sobre engajamento no trabalho mais influentes na década

\begin{tabular}{l|l|c|c|c}
\hline \multicolumn{1}{c|}{ Autores } & \multicolumn{1}{c|}{ Título da fonte } & $\begin{array}{c}\text { Ano da } \\
\text { publica- } \\
\text { ção }\end{array}$ & $\begin{array}{c}\text { Total de } \\
\text { citações }\end{array}$ & $\begin{array}{c}\text { Média anual } \\
\text { de citações }\end{array}$ \\
\hline $\begin{array}{l}\text { Christian, Michael S.; Garza, Ade- } \\
\text { la S.; Slaughter, Jerel E. }\end{array}$ & Personnel Psychology & 2011 & 779 & 77,90 \\
\hline $\begin{array}{l}\text { Stilgoe, Jack; Owen, Richard; } \\
\text { Macnaghten, Phil }\end{array}$ & Research Policy & 2013 & 582 & 72,75 \\
\hline $\begin{array}{l}\text { Nahrgang, Jennifer D.; Morgeson, } \\
\text { Frederick P.; Hofmann, David A. }\end{array}$ & $\begin{array}{l}\text { Journal of Applied Psycho- } \\
\text { logy }\end{array}$ & 2011 & 530 & 53,00 \\
\hline $\begin{array}{l}\text { Bakker, Arnold B.; Albrecht, Si- } \\
\text { mon L.; Leiter, Michael P. }\end{array}$ & $\begin{array}{l}\text { European Journal of Work } \\
\text { and Organizational Psy- } \\
\text { chology }\end{array}$ & 2011 & 416 & 41,60 \\
\hline $\begin{array}{l}\text { Bakker, Arnold B.; Demerouti, } \\
\text { Evangelia; Sanz-Vergel, Ana Isa- } \\
\text { bel }\end{array}$ & $\begin{array}{l}\text { Annual Review of Orga- } \\
\text { nizational Psychology and } \\
\text { Organizational Behavior }\end{array}$ & 2014 & 411 & 58,71 \\
\hline Aral, Sinan; Walker, Dylan & Management Science & 2011 & 295 & 29,50 \\
\hline
\end{tabular}

Fonte: dados da pesquisa (2020).

$\mathrm{O}$ artigo "Work engagement: a quantitative review and test of its relations with task and contextual performance", escrito por Christian, Garza e Slaughter (2011), influenciou muitos pesquisadores ao descobrirem que o engajamento exibe validade discriminante e validade relacionada a critérios sobre as atitudes no trabalho, cujos testes sobre o seu papel como mediador da relação entre antecedentes distais e desempenho no trabalho conferiram ao engajamento no trabalho um constructo útil.

No mesmo ano, Bakker, Albrecht e Leiter (2011) constataram que o contexto social é crucial e pode preparar o cenário para um clima de engajamento no trabalho, indicando, também, a existência de relação entre engajamento e saúde. Apoiando-se nesses achados, Porto-Martins, Basso-Machado e Benevides-Pereira (2013) afirmam que os estudos sobre engajamento no trabalho devem ter foco, prioritariamente, na saúde, explorando temas como síndrome de Burnout. Assim, forma-se uma corrente teórica do engajamento no trabalho com ênfase nos resultados da saúde. Por outro lado, Bakker, Tims e Derks (2012) e Liao et al. (2013), entre outros, desenvolvem estudos com ênfase nos resultados motivacionais, formando uma corrente teórica que explora os traços da personalidade das pessoas e os aspectos das trocas sociais para aumentar o envolvimento das pessoas no trabalho.

Conforme consta na tabela 2, outros autores contribuíram para o avanço dos estudos sobre engajamento no trabalho, com menor representatividade comparativamente a Arnold B. Bakker (62 citações). Entre eles, estão Daantje Derks (12 citações), Evangelia Demerati (11 citações) e Maria Tims (9 citações). Todos esses autores são coautores dos trabalhos publicados por Arnold B. Bakker. 
Tabela 2 -Análise de resultados para o campo autores

\begin{tabular}{l|c|c}
\hline \multicolumn{1}{c|}{ Autores mais citados } & $\begin{array}{c}\text { Contagem } \\
\text { do } \\
\text { registro }\end{array}$ & \% de 62 \\
\hline BAKKER, A. B. & 62 & $100.000 \%$ \\
\hline DERKS, D. & 12 & $19.355 \%$ \\
\hline DEMEROUTI, E. & 11 & $17.742 \%$ \\
\hline TIMS, M. & 9 & $14.516 \%$ \\
\hline XANTHOPOULOU, D. & 7 & $11.290 \%$ \\
\hline OERLEMANS, W. G. M. & 5 & $8.065 \%$ \\
\hline COSTA, P. L. & 4 & $6.452 \%$ \\
\hline PASSOS, AM & 4 & $6.452 \%$ \\
\hline VAN WINGERDEN, J & 4 & $6.452 \%$ \\
\hline ALBRECHT, S. L. & 3 & $4.839 \%$ \\
\hline PETROU, P. & 3 & $4.839 \%$ \\
\hline SANZ-VERGEL, A. I. & 3 & $4.839 \%$ \\
\hline SONNENTAG, S. & 3 & $4.839 \%$ \\
\hline VAN GELDEREN, B. R. & 3 & $4.839 \%$ \\
VAN WOERKOM, M. & 3 & $4.839 \%$ \\
\hline FOS
\end{tabular}

Fonte: dados da pesquisa (2020).

Quanto aos países/regiões de origem dos autores supracitados, foi verificada a supremacia dos Países Baixos (62 registros) comparativamente à África do Sul ( 9 registros) e China ( 8 registros). Grécia, Espanha, Austrália, Alemanha, Portugal e Estados Unidos possuem 4 registros cada, além de outros identificados na tabela 3.

Tabela 3 - Países/regiões de origem dos principais autores das publicações

\begin{tabular}{l|c|c}
\hline Países/Regiões & $\begin{array}{c}\text { Contagem } \\
\text { do registro }\end{array}$ & \% de 62 \\
\hline Países Baixos & 62 & $100,00 \%$ \\
\hline África do Sul & 9 & $14,51 \%$ \\
\hline $\begin{array}{l}\text { República Popular da } \\
\text { China }\end{array}$ & 8 & $12,90 \%$ \\
\hline Grécia & 6 & $9,67 \%$ \\
\hline Espanha & 6 & $9,67 \%$ \\
\hline Austrália & 4 & $6,45 \%$ \\
\hline Alemanha & 4 & $6,45 \%$ \\
\hline Portugal & 4 & $6,45 \%$ \\
\hline $\begin{array}{l}\text { Estados Unidos da } \\
\text { América }\end{array}$ & 4 & $6,45 \%$ \\
\hline Canadá & 3 & $4,83 \%$ \\
\hline Inglaterra & 3 & $4,83 \%$ \\
\hline Croácia & 2 & $3,22 \%$ \\
\hline Noruega & $3,22 \%$ \\
\hline Fon:
\end{tabular}

Fonte: dados da pesquisa (2020).
A representatividade dos Países Baixos na publicação é explicada pelo vínculo institucional do autor mais citado na última década nas publicações internacionais sobre engajamento no trabalho, Arnold B. Bakker. Na qualidade de professor e líder do grupo de pesquisa "Psicologia Organizacional e do Trabalho" do Instituto de Psicologia da Universidade, Erasmus de Roterdã, na Holanda, Arnold B. Bakker conduz projetos de pesquisa e, em suas publicações, seus alunos/orientandos figuram como coautores, a exemplo de Daatje Derks, Evangelia Demerouti, Maria Tims, Depoina Xanthopoulou. Outras universidades de origem das publicações estão identificadas na tabela 4.

Tabela 4 - Universidade de vínculo dos autores das publicações

\begin{tabular}{l|c|c}
\hline \multicolumn{1}{c|}{$\begin{array}{c}\text { Organizações - } \\
\text { Consolidada }\end{array}$} & $\begin{array}{c}\text { Contagem } \\
\text { do } \\
\text { registro }\end{array}$ & $\begin{array}{c}\text { \% de } \\
\mathbf{2 , 7 9 7}\end{array}$ \\
\hline $\begin{array}{l}\text { Erasmus University } \\
\text { Rotterdam }\end{array}$ & 92 & $3.289 \%$ \\
\hline University of London & 58 & $2.074 \%$ \\
\hline $\begin{array}{l}\text { State University System } \\
\text { of Florida }\end{array}$ & 54 & $1.931 \%$ \\
\hline Utrecht University & 49 & $1.752 \%$ \\
\hline $\begin{array}{l}\text { Eindhoven University Of } \\
\text { Technology }\end{array}$ & 46 & $1.645 \%$ \\
\hline $\begin{array}{l}\text { Indian Institute of } \\
\text { Technology System Iit } \\
\text { System }\end{array}$ & 40 & $1.430 \%$ \\
\hline Ku Leuven & 38 & $1.359 \%$ \\
\hline Tilburg University & 34 & $1.216 \%$ \\
\hline $\begin{array}{l}\text { Pennsylvania } \\
\text { Commonwealth System of }\end{array}$ & 32 & $1.144 \%$ \\
\hline Higher Education Pcshe & 31 & $1.108 \%$ \\
\hline $\begin{array}{l}\text { University of North } \\
\text { Carolina }\end{array}$ & 29 & $1.073 \%$ \\
\hline $\begin{array}{l}\text { Vrije Universiteit } \\
\text { Amsterdam }\end{array}$ & $1.037 \%$ \\
\hline $\begin{array}{l}\text { Eastern Mediterranean } \\
\text { University }\end{array}$ & $26.930 \%$ \\
\hline Monash University & $\begin{array}{l}\text { California State } \\
\text { University System }\end{array}$ & $291 \%$ \\
\hline
\end{tabular}




\begin{tabular}{|l|c|c|}
\hline $\begin{array}{l}\text { University of Texas } \\
\text { System }\end{array}$ & 26 & $0.930 \%$ \\
\hline $\begin{array}{l}\text { Copenhagen Business } \\
\text { School }\end{array}$ & 25 & $0.894 \%$ \\
\hline Griffith University & 25 & $0.894 \%$ \\
\hline University Of Jyvaskyla & 25 & $0.894 \%$ \\
\hline $\begin{array}{l}\text { University System of } \\
\text { Georgia }\end{array}$ & 25 & $0.894 \%$ \\
\hline University of Amsterdam & 23 & $0.822 \%$ \\
\hline $\begin{array}{l}\text { North West University } \\
\text { South Africa }\end{array}$ & 22 & $0.787 \%$ \\
\hline $\begin{array}{l}\text { Royal Melbourne } \\
\text { Institute of Technology } \\
\text { Rmit }\end{array}$ & 22 & $0.787 \%$ \\
\hline $\begin{array}{l}\text { Pennsylvania State } \\
\text { University }\end{array}$ & 21 & $0.751 \%$ \\
\hline University of Auckland & 21 & $0.751 \%$ \\
\hline University of Bath & & \\
\hline Fonte: dados da pesquisa & $2020)$ & \\
\hline
\end{tabular}

Fonte: dados da pesquisa (2020).

Com vínculo institucional dos autores à University of London está o artigo "The relationship between line manager behavior, perceived HRM practices, and individual performance: examining the mediating role of engagement", de autoria de Alfes et al. (2013). Trata-se de um estudo que examinou o papel desempenhado pelos gerentes de linha em relação às práticas da área de onde estão as pessoas e as respostas de desempenho individual, cujos resultados confirmaram o papel mediador do gerente entre as práticas de gestão de pessoas e desempenho/envolvimento individual dos funcionários.

\section{CONSIDERAÇÕES FINAIS}

O estudo foi conduzido com o objetivo de pesquisar a produção científica sobre engajamento no trabalho (EGT) por meio das publicações depositadas na base de dados Web of Science do Institute for Scientifuc Information (WOS/ISI), no período de 2011 a 2020. Engajamento é um estado positivo da mente, realizador e relacionado ao trabalho, cujas características são vigor, dedicação e absorção. Desse estado positivo, decorrem emoções positivas, como felicidade, alegria, otimismo, autoconfiança e outras.

Os resultados da pesquisa bibliométrica, que tomou a Web of Science (WOS) Coleção Principal como base de dados para mapear a produção internacional de artigos sobre engajamento no trabalho, por conter todas as revistas que estão no Journal Citation Reports (JCR), indicou publicações realizadas em diferentes áreas do conhecimento. Contudo, a presença do tema nos estudos no campo da educação gerou inquietação, tendo em vista que, tradicionalmente, os estudos da área da administração apresentam interface temática com a área da psicologia.

Quanto ao volume de publicações sobre engajamento no trabalho, constatou-se crescimento linear no período 2011 a 2020, com crescimento mais significativo a partir do ano 2015, quando o crescimento foi de 78 artigos comparativamente ao ano anterior.

$\mathrm{O}$ artigo mais influente da década (779 citações) foi escrito por Christian, Garza e Slaughter (2011); contudo, o autor mais influente foi Arnold B. Bakker, por ser coautor em nove dos 50 artigos mais citados. Ainda, os achados apontam para consolidação de métodos e instrumentos de coleta a partir do que é produzido por Arnold B. Bakker e sua equipe de pesquisa, o que pode sugerir linearidade com apenas uma corrente teórica.

Desse modo, a ausência de um conjunto de autores referência no assunto para além daqueles que trabalham com Arnold B. Bakker se apresenta como uma limitação para exploração de outros contextos. Mesmo reconhecendo que houve avanços epistemológicos e metodológicos significativos no campo de estudos, o desenvolvimento de uma ciência é mais robusta quando se dá pelos seus contrários. Por essa lógica, a originalidade do estudo reside na contribuição para a reflexão crítica sobre os avanços identificados na última década, contudo por uma única lente teórica e conduzida por um grupo de pesquisadores de apenas um vínculo institucional.

Contribuições do estudo e sugestões de estudos futuros. Os resultados da biblio- 
metria contribuem para os pesquisadores refletirem a respeito do desenvolvimento do campo de pesquisa sobre EGT para além da visão dos pesquisadores europeus. Retomar o framework conceitual elaborado por Christian, Garza e Slaughter (2011) pode ser, especialmente, útil para revisar os antecedentes distais que estão sendo considerados nas pesquisas sobre EGT a partir da realidade brasileira no contexto pós-pandemia Covid-19. As características do trabalho estão se alterando substancialmente, e as práticas de trabalho passaram a exigir mais percepção de política do que consta nos estudos sobre EGT desenvolvidos até então.

\section{REFERÊNCIAS}

ALFES, K. et al. The relationship between line manager behavior, perceived HRM practices, and individual performance: examining the mediating role of engagement. Human Resource Management, v. 52, n. 6, p. 839-859, 2013. https://doi.org/10.1002/hrm.21512

ANGST, R.; BENEVIDES-PEREIRA, A. M. T.; PORTO-MARTINS, P. C. UWES Manual, Português BR. Escala de engagement no trabalho de Utrecht. [S.l.: s.n.], 2009.

ARAÚJO, C. A. Bibliometria: evolução histórica e questões atuais. Em Questão, Porto Alegre, v. 12, n. 1, p. 11-32, 2006.

BAKKER, A. B. An evidence-based model of work engagement. Current Directions in Psychological Science, v. 20, n. 1, p. 4-28, 2011.

BAKKER, A. B.; ALBRECHT, S. L.; LEITER, M. P. Key questions regarding work engagement. European Journal of Work and Organizational Psychology, v. 20, n. 1, p. 4-28, 2011.

BAKKER, A. B.; DEMEROUTI, E.; SANZ-VERGEL, A. I. Burnout and work engagement: the JD-R approach. Annual Review of Organizational Psychology and Organizational Behavior, v. 1, p. 389-411, 2014. https://doi.org/10.1146/annurev-orgpsych-031413-091235
BAKKER, A. B.; TIMS, M.; DERKS, D. Proactive personality and job performance: the role of job crafting and work engagement. Human Relations, v. 65, n. 10, p. 1359-1378, 2012.

BAKKER, A. B.; XANTHOPOULOU, D. The crossover of daily work engagement: test of an actor-partner interdependence model. Journal of Applied Psychology, v. 94, n. 6, p. 15621571, 2009.

CHÉR, R. Engajamento: melhores prática de liderança, cultura organizacional e felicidade no trabalho. Rio de Janeiro: Alta Books, 2016.

CHRISTIAN, M. S.; GARZA, A. S.; SLAUGHTER, J. E. Work engagement: a quantitative review and test of its relations with task and contextual performance. Personnel Psychology, v. 64, n. 1, p. 89-136, 2011.

CHUEKE, G. V.; AMATUCCI, M. O que é bibliometria? Uma introdução ao Fórum. Revista Eletrônica de Negócios Internacionais, v.10, n. 2, p. 1-5, maio/ago. 2015.

CONSTÂNCIO, F. L.; SOUZA NETO, J. Correlação entre o nível de engajamento das equipes de projeto e o desempenho em uma empresa pública estruturada por projetos. Revista de Gestão e Projetos, v. 7, n. 2, p. 16-33, 2016. Doi: $10.5585 /$ gep.v7i2.340

FIORENTIN, B. E.; STEFANO, S. R.; SANTOS, J. S. Engajamento no trabalho: análise bibliométrica da produção científica internacional. Revista Gestão em Análise, v. 9, n. 1, p. 48-63, fev. 2020. Doi: 10.12662/2359-618xregea.v9i1.p48-63.2020.

GONZÁLEZ-ROMA, V. et al. Burnout e o trabalho engajamento: fatores independentes ou pólos opostos? Jornal de Comportamento Profissional, n. 68, p.165-174, 2006.

GUERRAZZI, L. A. C. et al. Um estudo bibliométrico sobre declínio organizacional em ambiente empreendedor: perspectivas e tendências. Revista da Micro e Pequena Empresa, v. 11, n. 2, p. 72-88, 2017. 
HANSEN, R. et al. Inteligência emocional e engajamento no ambiente de trabalho: estudo empírico a partir de trabalhadores gaúchos. Revista Gestão Organizacional, v. 11, n. 1, p. 1-22, jan./abr. 2018.

KNIGHT, Caroline; PATTERSON, Malcolm; DAWSON, Jeremy. Building work engagement: a systematic review and meta-analysis investigating the effectiveness of work engagement interventions. Journal of Organizational Behavior, v. 38, n. 6, p. 792-812, 2017.

KAHN, W. A. Psychological conditions of personal engagement and disengagement at work. Academy of Management Journal, v. 33, n. 4, p. 692-724, 1990.

LIAO, F. Y. et al. Team-member exchange and work engagement: does personality make a difference? Journal of Business and Psychology, v. 28, p. 63-77, 2013.

MÄKIKANGAS, A. Job crafting profiles and work engagement: a person-centered approach. Journal of Vocational Behavior, v. 106, p. 101-111, June 2018.

MASLACH, C.; SCHAUFELI, W. B.; LEITER, M. Job burnout. Annual Review of Psychology, v. 52, p. 397-422, 2001.

MORAES, R. M.; TEIXEIRA, A. J. C. Gestores, engajamento e comportamentos políticos: uma relação não linear. Revista de Administração Contemporânea, v. 24, n. 3, art. 2, p. 218-231, 2020.

MOURA, L. R. N. I.; CHARÃO-BRITO, L.; LOPES, L. F. D. Vigor, dedicação, absorção: uma análise da percepção de profissionais pós-graduandos sobre engajamento no trabalho. Revista Cesumar Ciências Humanas e Sociais Aplicadas, v. 22, p. 229-245, 2017.

NAHRGANG, J. D.; MORGESON, F. P.; HOFMANN, D. A. Safety at work: a meta-analytic investigation of the link between jobdemands, job resources, burnout, engagement, and safety outcomes. Journal of Applied Psychology, v. 96, n. 1, p. 71-94, 2011.
OBREGON, S. L. et al. Engajamento no trabalho: uma análise das publicações da última década. In: SEMINÁRIOS EM ADMINISTRAÇÃO, 19., 2016, São Paulo. Anais [...]. São Paulo: FEA/USP, 2016.

OLIVEIRA, L. B.; ROCHA, J. C. Engajamento no trabalho: antecedentes individuais e situacionais e sua relação com a intenção de rotatividade. Revista Brasileira de Gestão de Negócios, v. 19, n. 65, p. 415-431, 2017.

PORTO-MARTINS, P.C.; BASSO-MACHADO, P. G.; BENEVIDES-PEREIRA, A. M. T. Engagement no trabalho: uma discussão teórica. Fractal, Revista de Psicologia, v. 25, n. 3, p. 629-644, 2013.

QUEVEDO-SILVA, F. et al. Estudo bibliométrico: orientações sobre sua aplicação. Brazilian Journal of Marketing - BJM. Revista Brasileira de Marketing - ReMark, v. 15, n. 2. abr./jun. 2016.

RODRÍGUEZ-MONTALBÁN, R.; MARTÍNEZ-LUGO, M.; SÁNCHEZ-CARDONA, I. Análisis de las propiedades psicométricas de la Utrecht Work Engagement Scale en una muestra de trabajadores en Puerto Rico. Universitas Psychologica, v. 13, n. 4, p. 12551266, 2014.

SCHAUFELI, W. B. et al. The measurement of engagement and burnout: a two sample confirmatory factor analytic approach. Journal of Happiness Studies, v. 3, n. 1, p. 71-92, 2002.

SHAUFELI, W.; BAKKER, A. UWES Utrecht Work Engagement Scale: preliminary manual. Versão 1, Occupational Health Psychology Unit, Utrecht University, Nov. 2003.

SCHAUFELI, W. B.; BAKKER, A. B. Defining and measuring work engagement: bringing clarity to the concept. In: BAKKER, A. B.; LEITER, M. P. (ed.). Work engagement: a handbook of essential theory and research. New York: Psychology, 2010. p. 10-24. 
SCHAUFELI, W.; DIJKSTRA, P.; VASQUEZ, A. C. O engajamento no trabalho. São Paulo: Casa do Psicólogo, 2013.

SELIGMAN, M. E. P.; CSIKSZENTMIHALYI, M. Positive psychology: an introduction. American Psychologist, v. 55, n. 1, p. 5-14, 2001.

SILVA, M. R.; HAYASHI, C. R. M.; HAYASHI, M. C. P. I. Análise bibliométrica e cientométrica: desafios para especialistas que atuam no campo. InCID: Revista de Ciência da Informação e Documentação, v. 2, n. 1, p. 110-129, 2011.

STILGOE, J.; OWEN, R.; MACNAGHTEN, P. Developing a framework for responsible innovation. Research Policy, v. 9, n. 42, p. 15681580, 2013.

VASCONCELOS, Y. L. Estudos bibliométricos: procedimentos metodológicos e contribuições. Revista de Ciências Jurídicas e Empresariais, v. 15, n. 2, p. 211-220, 2014.
VAZQUEZ, A. C. S.; HUTZ, C. S. (org.). Aplicações da psicologia positiva. São Paulo: Hogrefe, 2018.

VENZ, L.; PUNDT, A.; SONNENTAG, S. What matters for work engagement? a diary study on resources and the benefits of selective optimization with compensation for state work engagement. Journal of Organizational Behavior, v. 39, n. 1, p. 26-38, 2017.

WANG, Z.; LI, C.; LI, X. Resilience, Leadership and work engagement: the mediating role of positive affect. Social Indicators Research, v. 132, p. 699-708, 2017. 